\title{
Effects on self-efficacy for managing chronic pain and fatigue of rheumatoid arthritis following a group educational programme (based) on occupational therapy
}

\begin{abstract}
This study analyzes pain features in rheumatoid arthritis and the most relevant aspects that underlie occupational therapy intervention, to subsequently define an educational intervention model based on group occupational therapy. It also seeks to improve selfefficacy scores related to pain and fatigue management in an experimental group of 31 patients diagnosed with rheumatoid arthritis (compared with a control group of 31 patients, randomly distributed). The results reveal statistical significance $(p<0.001)$ in assessing selfefficacy, allowing us confirm the effectiveness of the experimental intervention.
\end{abstract}

Keywords: rheumatoid arthritis; occupational therapy, pain, fatigue, self-efficacy
Volume 3 Issue 5 - 2018

\section{Ricardo Moreno-Rodríguez, José Luis López- Bastias, Inmaculada Garrote Camarena, Carlos Goicoechea García.}

Unit of Support for students with disabilities and Special Educational Needs, Rey Juan Carlos University, Spain

Correspondence: Ricardo Moreno-Rodríguez, Professor, Designation Person in charge of Unit of attention to students with disabilities, University Rey Juan Carlos, Spain, Tel +34914888566, Email ricardo.moreno@urjc.es

Received: August 31, 2018 | Published: September II, 2018

\section{Pain in rheumatoid arthritis}

Rheumatoid arthritis follows a pattern of inflammatory process, also called arthritis pattern. It is normally accompanied by numbness after a more or less long period of immobilization. ${ }^{1}$ This pain usually lasts the patient's entire day, generally worsening with exercise and daily activities, although persistent even with rest, and of maximum intensity at night time. ${ }^{2}$

Overall, it is important to point out that the reduction of inflammation implies a decrease in pain, except in those situations in which structural joint damage has already occurred. Pain intensity varies, but it is often persistent and disabling. During the initial stages, predominant pain is of inflammatory nature, with polyarticular symmetric distribution in addition to hands and feet affectation. Morning stiffness has been a hallmark of this disease, persistent in the affected joints, resulting in an increase in pain at rest and decreasing it as the patient moves around. ${ }^{3-5}$ In such cases, pharmacological treatment may reduce inflammation but not the impact of pain. ${ }^{6-10}$

Arthritis pain is characterized by hyperalgesia and spontaneous pain. The first one (hyperalgesia) appears when moving the joint in its normal range of motion and when gentle pressure is applied to the joint. It is widely believed that this increased pain sensitivity is produced by nociceptor sensitisation. Inflammation in joints causes not only peripheral sensitisation (increased sensitivity of primary afferent nociceptive neurons/neurones) but also central sensitization (central nervous system hyperexcitability of neurons). Sensitisation can also promote efferent neuronal processes through which the nervous system influences the inflammatory process. ${ }^{11-12}$

Some psychosocial factors play a crucial role in pain chronofication as well as the perception of pain intensity ${ }^{16}$ such as depression or anxiety, ${ }^{17}$ catastrophism, ${ }^{18,19}$ negativism, ${ }^{20}$ beliefs about pain, ${ }^{20,21}$ religiosity and spiritual beliefs, ${ }^{22,23}$ anger management, ${ }^{24}$ and knowledge and understanding of the disease..$^{25,26}$

\section{Occupational therapy intervention model to address chronic pain caused by arthritis rheumatoid}

This model proposes a direct relation between occupation and the existence of cycles of chronic pain. Based on the model approaches, the primary objective of occupational therapy will be to increase the occupational behaviour of individuals with chronic pain. Using assessment tools, such as the occupational questionnaire, list of interests, list of roles and the occupational history of the person, enable us to understand the patient state of occupational equilibrium or disequilibrium. Moreover, these tools provide a work framework, oriented to maximize his/her occupational performance, and, by extension, the quality of life and state of health. ${ }^{27}$

Some of the most frequently used techniques resulted from occupational therapy to address pain are the following: participation in activities, preparing for the conduction of daily life activities, relaxation training, stress management techniques, coping skills training, art therapy and performance of creative activities. ${ }^{28-34}$

The specific role of occupational theory for the management of chronic pain is to increase the function of patients, just as reducing the individual's own pain and to increase their repertoire of skills in order to tolerate the activity while minimizing attention to pain. ${ }^{33}$ In this way, the main objective of the treatment is to maintain an adequate occupational balance in the different areas of performance, in order to maintain a correct quality of life.

Thus, the treatment aims to increase tolerance for the individual's activity being conducted on participation. This is put into practice involving an experimental group of 31 patients in a graded activity programme (compared with a control group of 31 patients, randomly distributed), starting with a painless activity level to gradually increasing the level of activity to the utmost of their own tolerance. Simultaneously, patients are trained in strategies and skills to properly organize their time and activities, so they can incorporate the observance of rest times before the pain begins into their lifestyles. ${ }^{33,34}$ 
Additionally, the intervention includes training contents on diverse aspects such as the nature of pain, strategies to protect joints and parts of the body suffering from the effects of pain, appropriate energy consumption, and, finally, training in the use of assistive devices and technical aids. ${ }^{35}$ In those cases in which pain is moreover further compounded by the presence of an anxiety disorder, self-instructions and relaxation training are also considered and provided.

One of the most relevant skills that require training is self-efficacy The individual's beliefs in his or her ability to control and manage pain is positively related to improved physical function, increased activity levels and lower levels of disability. ${ }^{36-40}$ It is also related to lower pain intensity and greater pain tolerance. ${ }^{41,37,42,43}$ Consideration has been given to self-efficacy in the performance of activities among people with chronic pain, with emphasis placed on the relation between greater self-efficacy and a predominance of pain-coping skills. ${ }^{44,45}$

The intervention as indicated in previous published works, ${ }^{46-48}$ included continuous assessment tasks from week to week and, additionally, homework for patients to do for the next session. Occupational therapy treatment is based not only on analyzing daily performance and occupational balance of each patient, but also it pursued its readjustment according to energy demands. Furthermore, this intervention focused on examining and properly implement break times as well as training their performance of activities and principal occupations effectively and efficiently with the aim of lessening the impact of disease, and also, the consequences of poor management resulting of both, time and energy.

\section{The structure of the programme included:}

i. Presentation. How does arthritis affect our activity?

ii. Organizing work time, occupational balance and identifying interests.

iii. Analysis of activities in order to carry them out in simple steps.

iv. Energy consumption and rest periods I: technical training and energy management.

v. Energy consumption and rest periods II: Analysis of results and relax.

vi. Leisure and physical activity.

vii. Economics and joint protection.

The Visual Analog Scale for Pain was used for the measurement of pain, and the Spanish version of the Arthritis Self-efficacy Scale, available from the Stanford Patient Education Research Center, was used to measure patient's self-efficacy and perception towards their control of the disease, specifically, arthritis rheumatoid..$^{49}$ In addition, an ad hoc questionnaire was used; it was composed of 20 questions with three possible answer options (quantifiable as "greater than", "same as" or "less than"). It offered a Cronbach's alpha reliability estimate of 0.816 , in order to collect the subjective experience of patients concerning diverse aspects such as: the quality of life, pain intensity, inflammation, management of pain and inflammation, stress management or psychological tension, taking medicines and the perceived usefulness from the intervention, among others.

\section{Results}

At the end of the treatment, as previously mentioned, the final questionnaire was administered and designed ad hoc, including different items for the assessment of the subjective perception of pain and pain-management skills. The chi-square test for items 7 and 8 did not show significant differences according to the level of pain, in general terms, produced by rheumatoid arthritis $(\mathrm{p}=0.59)$; but, on the contrary, significant results were obtained referring to the levels of pain after performing daily activities $(\mathrm{p}=0.048)$. The comparative analysis of the variability of pain scores obtained through both the Mann-Whitney U test and the VAS, show that no significant differences were found. Similarly, the results obtained from the comparison of the scores recorded with the VAS when the experimental group evolution was analyzed separately during carrying out the Wilcoxon test $(p=0,376)$ this test detected significant differences in the control group ( $\mathrm{p}=0.005)$, perhaps due to the symptomatic worsening.

With regard to self-efficacy, statistically significant differences were found for the overall quality of life score at the end of treatment $(\mathrm{p}=0.001)$, specifically, in both the Mann-Whitney $\mathrm{U}$ test and the Wilcoson test.

On the other hand, the final questionnaire also included aspects related to self-efficacy, in which the participants of the experimental group were asked about their ability to apply trained techniques for symptom control of rheumatoid arthritis. To this end, The Pearson chi-square test was performed to determine the results.

Finally, $96,7 \%$ of the individuals participating in this study indicated that they felt more able to control their levels of anxiety $(p<0.001)$ when they were asked about this aspect during the posttreatment assessment; only 3,3\% of participants felt as capable as before. The data resulting from all these techniques allowed us to find significant differences in terms of the level of general tiredness $(p=0.007)$ as well as the level of tiredness after doing daily activities $(\mathrm{p}<0.001)$.

At the end of the post-treatment assessment, $90 \%$ of the subjects from the experimental group pointed out that they were more careful with gestures and movements performed $(\mathrm{p}<0.001)$ compared to $10 \%$ of them who indicated that they maintained the same degree of care as before the treatment.

In respect of their ability to control inflammation, $66,7 \%$ of subjects felt more able to control inflammation by themselves $(\mathrm{p}=0.048)$ compared to $33,3 \%$ of participants who felt as capable as before finishing the workshop. With regard to pain control, $80 \%$ of patients stated that they felt more able to control pain by themselves in the post- assessment $(\mathrm{p}=0.0001)$ and $20 \%$ felt that they were equally able.

\section{Discussion}

It is well known that the application of self-management programmes that include physical activity plans leads to improvements in pain, self-efficacy and fatigue scores ${ }^{50,34}$ once the intervention is over. However, follow-up evaluations of these studies showed a decrease in self-efficacy scores, which implies that these results were not sustained over time. These studies, based on others carried out along the same lines, ${ }^{51-53}$ showed an improvement in selfefficacy scores, but were weak in terms of maintaining the effects obtained. This weakness could be due to the fact that the interventions developed focused on techniques that do not undermine daily performance of patients, making it difficult to generalize the strategies trained in a controlled environment to real life and leading to a poor implementation of those techniques. As a consequence, patients could not see their usefulness. Moreover, there was neither good adherence 
nor strong interest by the participants of the programme, since the interventions were not based on meaningful activities for them.

The occupational therapy intervention proposed in our study is specifically aimed at the daily and personal life of each participant, which allows patients to apply the techniques in daily performance, in their occupational repertoire, and the activities and occupations that are essential for each one of the patients. It allows not only to measure the effectiveness of the impact in an uncontrolled and realworld setting, but also promotes the maintenance of results achieved more efficiently than in similar studies identified above.

In the analysis of results, highly significant differences have been found with respect to the levels of self-efficacy measured after the intervention $(p<0.001)$, meaning that patients feel more capable of managing, facing and coping with pain and fatigue in their daily lives, as well as participants feel that they carry out daily activities more effectively.

Furthermore, when analyzing the differences within the same group, highly significant differences were found $(p<0.001)$, since the scores obtained in the post-treatment assessment are better than those obtained by the group during the basal evaluation. Highly significant differences $(p<0.001)$ have also been observed in the control group when studying the difference between the post-treatment assessment and basal evaluation, mainly due to a worsening of self-efficacy scores. This has come about because of the exacerbation of the research variables: by increasing pain scores with regard to the basal evaluation, the sense of self-efficacy for managing pain or fatigue are at a lower level (taking into consideration that the seasonal moments experienced by most patients resulted in a worsening of symptoms, both in the experimental and control group, as stated above.

These results may be because direct implementation of such techniques during the performance of daily life activities, in addition to the positive results obtained. All this promotes continuity in their execution, together with the repetition of the techniques which increase the competence of the patients, being more effective in obtaining results. These considerations are also endorsed by the data analysis from the questionnaire, specifically designed for the post-treatment assessment, where the members of the experimental group felt more able to control nervous tension and the type of movements they usually performed in their daily activities, managing pain and reducing general fatigue, including the one associated with carrying out daily activities. Thus, it can be said that there has been an improvement in self-efficacy scores for managing the disease manifestations with respect to the control group, and an improvement in the overall self-efficacy scores in the experimental group with respect to the basal assessment.

One can therefore conclude that the intervention designed to address chronic pain holds the key to equipping the patients with strategies and abilities/skills to manage the disease and its manifestations. At the same time, there had been an increase in self-efficacy of the individuals for managing chronic pain and fatigue.

\section{Acknowledgments}

None.

\section{Conflict of interest}

The author declares no conflict of interest

\section{References}

1. Álvarez L. El libro de la artritis reumatoide. Díaz de Santos. 2003.

2. http://www.ser.es/pacientes/enfermedades_reumaticas/artritis_ reumatoide.php 25-11-2011 GMT+1

3. Dekker J, Boot B, Van der WLH, et al. Pain and disability in osteoarthritis patients. A review of biobehavioral mechanism. Journal of Behavioral Medicine. 1992;15(2):189-214.

4. Chozas N, García PS. Dolor reumatológico. Patología degenerativa e inflamatoria básica. En: Torres L. Dolor musculoesquelético. Madrid: Ergon. 2003.

5. Kazis LE, Meenan RF, Anderson JJ. Pain in the rheumatic diseases: investigations of a key health status component. Arthritis Rheum.1982;26(8):1017-1022.

6. McKenna F. Pain and rheumatoid arthritis. Ann Rheum Dis. 1985;44(11):805-806.

7. Mense S. Nociception from skeletal muscle in relation to clinical muscle pain. Pain.1983;54:241-290.

8. Riedemann P. Guía clínica artritis reumatoidea. Ministerio de Salud. Santiago, Minsal; 2007.

9. Schaible HG, Grubb BD. Afferent and spinal mechanism of joint pain. Pain.1993;55(1):5-54.

10. http://external.doyma.es/pdf/4/4v20n08a13018371pdf001.pdf

11. Neira F, Ortega JL. Tratamiento del dolor en la artritis reumatoide fundamentado en la medicina basada en la evidencia. RevSocEsp Dolor. 2006;13(8):561-566.

12. Laffon RA. Epidemiología, etiopatogenia y manifestaciones clínicas. En: Manual SER de las enfermedades reumáticas. Editorial Médica Panamericana. Madrid. 2008.

13. Schaible HG, Vanegas H. Baillière's Clinical Rheumatology.2000;14(4):797-811.

14. Mense S. Nociception from skeletal muscle in relation to clinical muscle pain. Pain. 1993;54(3):241-290.

15. Mapp P. Inervations the synovium. Ann Rheum Dis.1995;54(5):398-403.

16. Meredith P, Ownsworth T, Strong J. A review of the evidence linking adult attachment theory and chronic pain: presenting a conceptual model. Clinical Psychology Review. 2008;28(3):407-429.

17. Young CC, Nicassio PM, Harpin RE, et al. Transition from acute to chronic pain and disability: a model including cognitive, affective, and trauma factors. Pain. 2008;134(1-2):69-79.

18. Michael ES, Burns JW.Catastrophizing and pain sensitivity among chronic pain patients: moderating effects of sensory and affect focus. Ann Behav Med. 2004;27(3):185-194.

19. Buer N, Linton S. Fear-avoidance beliefs and catastrophizing: occurrence and risk factor in back pain and ADL in the general population. Pain. 2002;99(3):485-491.

20. Stroud MW, Thorn BE, Jensen MP, et al. The relation between pain beliefs, negative thoughts, and psychosocial functioning in chronic pain patients. Pain. 2000;84(2-3):347-352.

21. DeGood D, Shutty MS. Assessment of pain beliefs, coping and selfefficacy. EN: Turk DC, Melzack R. Handbook of pain assessment. Guilford, New York. 1992

22. Rippentrop AE, Altamaier EM, Chen JJ, et al. The relationship between religion/spirituality and physical health, mental health, and pain in a chronic pain population. Pain. 2005;116(3):311-321. 
23. Glover G NM, Irmo M, Jeff B. Religious and spiritual beliefs and practices of persons with chronic pain. Rehabilitation Counseling Bulletin. 2007;51(1):21-33.

24. Burns JW, Bruehl S. Anger management style, opioid analgesic use, and chronic pain severity: a test of the opioid-deficit hypothesis. Journal of Behavioral Medicine. 2005;28(6):555-563.

25. Hammond A, Freeman K. The long-term outcomes from a randomized controlled trial of an educational-behavioral joint protection programme for people with rheumatoid arthritis. Clinical Rehabilitation. 2004;18(5):520-528.

26. Holman H, Lorig K. Patient education in the rheumatic diseases. Bull Rheum Dis.1987;37(5):1-8.

27. Kielhofner G. Modelo de ocupación humana. Madrid: Panamericana. 2011.

28. Klinger L, Spaulding S. Occupational therapy treatment of chronic pain and use ofassistive devices in older adults. Top GeriatrRehabil. 2001;16(3):34-44.

29. Brown C. Service users' and occupational therapists' beliefs about effective treatments for chronic pain: a meeting of the minds or the great divide?. Disability and Rehabilitation. 2003;25(19):1115-1125.

30. McCormack GL. Pain management by occupational therapists. American Journal of Occupational Therapy. 1988;42(9): 582-590.

31. Brown C. Occupational Therapists' beliefs regarding treatment options for people with chronic pain. British Journal of Occupational Therapy. 2002;65(9):398-404.

32. Unruh A. Teachingstudentoccupationaltherapistsaboutpain: a courseevaluation. Can J OccupTher. 1995;62(1):30-36.

33. Strong J. Chronic pain management: the occupational therapist's role. British Journal of Occupational Therapy. 1987;50(8):262-263.

34. Strong J. Chronic pain. The occupational therapist's perspective. Churchill Livingstone: 1996.

35. Klinger L, Spaulding S.Occupational therapy treatment of chronic pain and use of assistive devices in older adults. Top GeriatrRehabil. 2001;16(3):34-44.

36. Estlander AM, Vanharanta H, Moneta H, et al. Anthropometric variables, self efficacy beliefs and pain and disability ratings on the isokinetic performance of low back pain patients. Spine; 1994;19(8):941-947.

37. Jensen MP, Turner JA, Romano JM. Changes in beliefs, catastrophizing and coping are associated with improvement in multidisciplinary pain treatment. Journal of Consulting and Clinical Psychology. 2001;69(4):655-662.

38. Lorig K, Holman H. Arthritis self-management studies: a twelve year review. Health Education Quarterly.1993;20:17-28.

39. Rejesky WJ, Craven T, Ettinger WH Jr, et al. Self-efficacy and pain in disability with osteoarthritis of the knee. Journal of Gerontology Psychological Sciences. 1996;51(1):24-29.
40. Turner JA, Jensen MP, Romano JM. Do beliefs, coping and catastrophizing independently predict functioning in patients with chronic pain? Pain. 2000;85(1-2):115-125.

41. Dolce JJ. Self Efficacy and disability beliefs in behavioral treatment of pain. Behavior Research Therapy. 1987;25(4):289-299.

42. Keefe FJ, Kashikar ZkS, Salley A, et al. Pain coping strategies that predict patients' and spouses' ratings of patients' self-efficacy. Pain. 1997;73(2):191-199.

43. LittMD. Cognitive mediators of stressfull experience: self-efficacy and perceived control.Cognitive Therapy and Research. 1988;12(3):241260

44. Lorig K, Seleznick M, Lubeck D, et al.The beneficial outcomes of the arthritis self -management course are not adequately explained by behavior change. Arthritis and Rheumatism. 1989;32(1):91-95.

45. Lackner JM,Carosella AM, Feuerstein M. Pain expectancies, pain and functional self efficacy expectancies as determinants of disability in patients with chronic low back disorders. Journal of Consulting and Clinical Psychology. 1996;64(1): 212-220

46. Moreno RR, Bastias JLL, Camarena IG. A group education programme on occupational therapy in terms of improving the quality of life and chronic pain management for patients with rheumatoid arthritis. Int Phys Med Rehab J. 2018;3(3):221-222.

47. Moreno RR, Bastias JLL, Camarena IG. Effects of an educative programme based on occupational therapy in quality life of people with rheumatoid arthritis. International Journal of Current Advanced Research. 2017;2(12).

48. Moreno RR. Efectos de la intervención desde terapia ocupacional sobre la percepción del dolor crónico y la calidad de vida en pacientes con artritis reumatoide. Revista de la Sociedad Española de Dolor. 2015;22(3).

49. González VM, Stewart A, Ritter PL, et al. Translation and validation of arthritis outcome measures into Spanish. Arthritis and Rheumatism. 1995;38(10):1429-1446.

50. Callahan L., Mielenz T, Freburger J, et al. A randomized controlled trial of the people with arthritis can exercise program: Symptoms, function, physical activity, and psychosocial outcomes. Arthritis Care \& Research. 2008;59(1):92-101.

51. Lorig K, Laurin J, Holman HR. Arthritis self-management: a study of the effectiveness of patient education for the elderly. Gerontologist. 1984;24(5):455-457.

52. Lorig K. Arthritis patient education. En: Riggs G, Gall E, editors. Rheumatic diseases: rehabilitation and management. Woburn, MA: Butterworth;1984:289-298.

53. Riemsma RP, Kirwan JR, Taal E, et al. Patient education for adults with rheumatoid arthritis. Cochrane Database of Systematic Reviews. 2003;(2):CD003688. 